\title{
Bystander intervention: Group size and victim status*
}

\author{
VICTOR A. HARRIS and CAROL E. ROBINSON \\ State L'niversity of New York at Buffalo \\ Buffalo, N.Y. 14226
}

In the context of either a two- or four-person group discussion via an intercom system, female Ss overheard either a high- or low-status group member undergo an asthma attack. The prediction deriving from Latané and Darley's model-that reporting of the emergency would be quicker in the two- than in the four-person group-was supported. The prediction that independent of group size reporting would be quicker when the victim was high status, rather than low, was not.

The reason people fail to intervene in emergencies has been the focus of much recent experimental inquiry. One of the major findings of such research is that the greater the number of bystanders there are in an emergency situation, the longer it takes for any single bystander to intervene and the less likely intervention becomes (Darley \& Latané, 1968). To explain this phenomenon, Darley and Latané have devised a decision process model which argues that the possibility that a bystander will notice an event, recognize its nature as an emergency, or feel personally responsible decreases as the number of bystanders increases (Latané \& Darley, 1969).

A potentially important aspect of the decision process model is whether or not the bystander feels that the outcomes (rewards minus costs) associated with helping are more positive than the outcomes associated with not helping (Mogy \& Harris, 1971). Although Latané and Darley do not explicitly deal with a reward-cost analysis, such a schema is implicit in their overall model and fits in neatly with their more specific decision process model which contains as its last step the question, "Should I help?"

The present study was designed to provide information bearing both on the general helping model proposed by Latané and Darley as well as on the explicit reward-cost notion raised above. With regard to the Latané and Darley model, the present investigation provides for a close replication of Darley \& Latané's (1968) study which documented the inverse relationship between group size and helping in emergencies. Such a replication is worthwhile because of several procedural weaknesses in the original study which potentially weaken the impact of their results.

Darley and Latané's (1968) study involved Ss in a simulated group discussion during which one of the participants "suffered" an epileptic seizure. The general procedure was such that Ss believed they were part of a group of 2,3 , or 6 participants who were discussing personal problems faced by college students and whose

*Edward S. Katkin sponsors the above paper and accepts full editorial responsibility for it. discussion was not being monitored by the E. The Ss were told that each person would talk in turn, for about 2 min presenting her problems, and that then there would be sequential commenting by each participant. The order of discussion had the future victim speaking first and the naive $S$ last, and was regulated by a mechanical switching device which activated only one microphone at a time. After one complete sequence which was uneventful, the second round started with the victim having a "seizure." Thus the independent variable was the number of other people the $\mathrm{S}$ thought also heard the seizure, while the dependent measure was the time which lapsed from the start of the seizure until the $\mathrm{S}$ left her experimental cubicle.

The procedure outlined above (Darley \& Latané, 1968) suffers from two major flaws-one in the design of the group discussion and the other with regard to the collection of the dependent measure. Darley and Latané assume that because Ss got up and left their rooms their intentions were to report the emergency. We cannot rule out the possibility that these Ss were simply attempting to escape from the building, experiment, or the unpleasant situation. This may seem absurd; however, in light of responses elicited by real life situations, this behavioral possibility cannot be dismissed. If the E had not been sitting in the hall, but instead waited in a previously designated room, this behavioral possibility could have been subject to test. The present research employed the technique of explicitly stating where the $\mathrm{E}$ would be during the discussion.

The major problem arises with regard to Darley and Latané's regulation of the group discussion by means of a mechanical switching device. In the three- and six-person groups, the naive $\mathrm{S}$ was not the person whose microphone switched on after the victim's seizure; rather it would have been (one of) the other Ss' microphones. As Darley and Latané describe their procedure: "The victim's speech was abruptly cut off after 125 seconds, which could be interpreted by the subject that the time allotted for that speaker had elapsed and the switching circuit had switched away from him [1968, p. 379]." The problem that arises from such a procedure is one of credibility. How does the naive $S$ interpret the fact that the next speaker or speakers make no comment about the seizure, in fact make no comment at all? The silence could cause the $S$ to question the validity or plausibility of the seizure in particular and the experiment in general. Alternatively, the silence could have been interpreted as meaning that the next speaker had already gone to report the emergency and that, thus, further action would be unnecessary. Either or both of these alternatives could explain the different latencies in response obtained by Darley and Latane in that in the two-person, but only in the two-person, group, the naive $\mathrm{S}$ is always the "next" speaker; thus the incredibility and 
ambiguity would not have a chance to arise. One way to deal with this problem is to change the switching procedure so as to provide a plausible explanation for the lack of discussion or other comment following the victim's "seizure."

The second purpose of this study was to investigate the reward-cost model of helping. In the context of the group discussion paradigm, it was felt that manipulation of perceived status of the victim vis-a-vis the bystanders and among the bystanders would allow for investigation of the model. To the extent that high-status others can provide more rewards than equal- or low-status others, there should be greater felt pressure to aid when the victim is of higher status than the bystander. These considerations led to a six-celled design, which independently varied perceived group size (two or four persons), status of victim relative to $S$ (equal or higher) and, within four-person groups, status of other bystanders relative to the $\mathrm{S}$ (equal or higher).

It was hypothesized that (1) regardless of status differences, there would be more aiding (short latency in reporting emergency) in two-person than in four-person groups; (2) regardless of group size, high-status victims would elicit more aid than lower status victims. No firm predictions were made regarding the effects of status differences among bystanders, although it was felt that pressures to aid might be reduced when the $S$ is paired with high- rather than equal-status bystanders. In addition, Ss' views of the situation and the other participants were assessed.

\section{METHOD}

Subjects

The Ss were 46 female freshmen at SUNY at Buffalo who participated as partial fulfillment of an introductory psychology course requirement.

\section{Procedure}

The procedure, providing an apparent emergency within the context of a simulated group discussion. was modeled closely on that of Darley \& Latané (1968); the only changes involved (1) making the E's location explicit to Ss, (2) giving Ss the responsibility of switching their own microphones on and off, (3) ensuring that $S$ always spoke last, and (4) substituting a simulated asthma attack for the original's epileptic seizure. The $\mathrm{S}$ (in four-person groups, the $\mathrm{S}$ and two confederates) was told that she would interact with the other participants via an intercom system in separate rooms to avoid any possible embarrassment in the discussion (involving problems in college life). This procedure allowed for a tape-recorded simulation of the discussion and the emergency. Ss were also told that the $\mathrm{E}$ was not monitoring the discussion, as it was being tape-recorded for later analysis.

Ss were told they would find a panel in each of their rooms with four lights on top and a corresponding number below each light. Three of the lights would be red and one of the lights would be white. The order in which the Ss would speak during the discussion would be indicated by the position of the white light ("If the white light is over No. 1, then you are the first speaker"). The naive $S$ was always the last to speak (the white light was always over No. 2 in the two-person group, and over No. 4 in the four-person group. Ss were told that although the E did not have a speaker, she would remain in the control room, time each 2 -min segment, and operate the switching device.
When one speaker's allotted time was up. her white light would go out and the next speaker would get her signal to turn her microphone on and talk. Ss were told that if a $S$ failed to turn her microphone off whien her white light went out and the next speaker turned her microphone on, two signals would be trying to fit into one channel and therefore would jam the circuits. If this occurred, the Ss would be unable to hear the next speaker. This explained the $5 \mathrm{~min}$ of silence after the asthmatic attack.

The "victim" went first in the initial interchange and mentioned her asthmatic condition. The victim began the second round of discussion in normal fashion, quickly succumbed to a "severe asthma attack." and "collapsed to the floor" after $35 \mathrm{sec}$. The attack was followed by $5 \mathrm{~min}$ of silence. If the $\mathrm{S}$ reported the emergency within the 5 -min period, $E$ investigated and reported that everything was under control. All Ss completed a questionaire assessing (1) their ratings of the discussion on the dimensions of pleasantness, interestingness. and embarrassingness, and (2) their ratings of the other participants on the dimensions of similarity, intelligence, and likability. All Ss were then given an intensive debriefing.

\section{RESULTS}

The major dependent variable was the speed with which Ss in the various conditions reported the emergency to the $\mathrm{E}$. The raw data (time to respond in seconds) were first transformed to reduce the skewness of the distribution (see Darley \& Latané, 1968) and then subjected to analyses of variance. Hypothesis 1 , that the victim would receive help more quickly in the two- than in the four-person group, was supported $(F=5.67$ $\mathrm{df}=1,40, \mathrm{p}<.05)$. Hypothesis 2 , that the high-status victim would receive help more quickly than the low-status victim independent of group size, was not supported $(F<1)$. In fact, a significant interaction between group size and victim status $(F=5.12$, $\mathrm{df}=1,40, \mathrm{p}<.05)$ indicated that while the high-status victim's emergency was reported with the shortest latency in the two-person group, the same victim's emergency was reported with the longest latency in the four-person group. The difference between these latencies was highly significant $(\mathrm{t}=3.22, \mathrm{df}=21$, $\mathrm{p}<.01$ ). The latencies for reporting low-status victims' emergencies were intermediate between the above extremes and did not differ from each other. Looking only at the four-person groups, the differential bystander status had no effect on responding. However, within these same groups, there was a tendency for the low-status victim's emergencies to be reported more quickly than the high-status victim's $(\mathrm{F}=2.38$, $\mathrm{df}=1,26, \mathrm{p}<.10)$.

\section{DISCUSSION}

The pattern of findings reported above are of interest for several reasons. First, the replication of Darley \& Latane's (1968) results (Hypothesis 1) under conditions which provided a more adequate test lends support to their analysis of aiding in emergencies. However, the fact that the response latency was lower for two- than for four-person groups only when the victim was of high status relative to the $S$ indicates that the group size phenomenon may have less generality (even in laboratory settings) than was initially thought.

Secondly, the failure of the data to support Hypothesis 2. coupled with the finding that within four-person groups 
low-status victims' emergencies were reported more quickly than those of high-status victims, casts considerable doubt on our initial assumption about the relationship between status, rewards and costs, and aiding. Another possibility is that our manipulation of status (high status = first-year graduate student. low status = freshman) might not have had the desired impact. However, the postquestionnaire data indicate that the high-status victim was rated as slightly more intelligent $(F=2.44$, df $=1.40$, $.10<\mathrm{p}<20$ ) and as significantly more likable than the low-status victim $(F=4.73, \mathrm{df}=1,40, \mathrm{p}<.05)$.

Thus. the data bolster our confidence in the existence of the phenomenon of decreased aiding as a function of increasing group size, while at the same time raising further questions about the generality of the phenomenon and the dynamics which underlie it.

\section{REFERENCES}

Darley, J. M., \& Latané, B. Bystander interventio1. in emergencies: Diffusion of responsibility. Journal of Personality \& Social Psychology, 1968, 8, 377-383.

Latané, B., \& Darley, J. M. Bystander "apathy." American Scientist, $1969,57,244-268$.

Mogy, R. B., \& Harris, V. A. Factors influencing the development of altruistic behavior: $A$ review and reconceptualization. Unpublished manuscript, State University of New York at Buffalo, 1971.

(Received for publication April 23, 1973.)

\section{Keypecking by pigeons in an imperfect environment for autoshaping}

\section{R. M. GILBERT \\ Addiction Research Foundation, Toronto, Ont., Canada}

Keypecking under the usual autoshaping procedure was found to be less likely when the key light was unshielded and thus allowed autoshaping to a stimulus available inside the food magazine alcove. Some birds pecked, nevertheless, mostly near the beginning of the stimulus rather than near the end, when autoshaped keypecking usually occurs. Regular autoshaped keypecking can be explained in terms of respondent conditioning, even though the resulting behavior may not be advantageous to the pigeon. Pecking at the beginning of the stimulus, which precedes autoshaped behavior directed towards the food alcove, may require an explanation in terms of higher-order conditioning.

Pigeons are apt to peck a lighted key that signals food. The phenomenon was first explored systematically by Brown \& Jenkins (1968), who dubbed the process leading to the first peck "autoshaping." Moore (1971) reported informally that keypecking may not be autoshaped if the lamp that transilluminates the key is imperfectly shielded. He noted that lack of shielding could have been a factor in the results of a study by ten Cate (1923), who, according to Moore, was probably the first $E$ to expose pigeons to an autoshaping procedure. ten Cate's pigeons did not peck the key, or rather its equivalent. Instead they put their heads into the food alcove when the light came on, making what Moore described as anticipatory responses. Much to our annoyance, we made a similar finding, quite independently. During an autoshaping study, our pigeons persistently put their heads in the food hopper opening when, to be consistent with the Brown and Jenkins result, they should have been pecking the key. A subsequent comparison between birds that had a shielded lamp and birds that had an unshielded lamp showed clearly that the shielding facilitated keypecking. This comparison is reported here.

\section{METHOD \\ Subjects and Apparatus}

Eighteen 3-year-old male White Carneaux pigeons, experimentally naive and obtained 6 months earlier from the Palmetto Pigeon Plant, Sumpter, S.C., had been maintained at close to $80 \%$ of their respective free-feeding weights for about 3 months.

Three identical experimental chambers were used. Within each was a standard LeHigh Valley three-key "pigeon intelligence panel" (No.141-13), slotted into a chamber of the same dimensions as the Lehigh Valley Model 132-02. The two outside keys were taped over and unused. The center key was opaque and could be transilluminated by a bare $2.2-\mathrm{W}$ bulb, $25 \mathrm{~mm}$ behind the key. The bulb and its support could be totally enclosed by a black box that fitted snugly against the rear of the panel around the key and its supporting fixture. Across the 